\title{
UMA ANÁLISE DA ABORDAGEM TERRITORIAL NO ENSINO DE GEOGRAFIA, NA EDUCAÇÃO BÁSICA NO CENTRO DE ENSINO MÉDIO SANTA RITA DE CÁSSIA, PALMAS-TO
}

\author{
Silvaldo Quirino Tavares ${ }^{1}$ \\ Marcileia Oliveira Bispo ${ }^{2}$
}

\begin{abstract}
Resumo
Este trabalho realiza algumas reflexões sobre a abordagem e compreensão do território no Ensino de Geografia na Educação Básica. O principal objetivo da pesquisa foi identificar como o Centro de Ensino Médio Santa Rita de Cássia, de Palmas -TO está apresentando o tema em questão e qual noção os alunos das séries finais do Ensino Básico estão tendo de território. A partir daí, identificar as principais dificuldades e propor sugestões. As considerações aqui presentes, têm como base pesquisas bibliográficas sobre o tema e a realização de um estudo de caso na escola, no ano de 2015. Conclui-se que o ensino do referido conceito geográfico na Educação Básica necessita ser revisto e aprofundado. $\mathrm{O}$ território precisa ser ensinado na escola em uma dimensão mais ampla do seu significado e das relações sociais em que está presente.
\end{abstract}

Palavras-chave: Território; Educação Básica; Geografia.

\section{AN ANALYSIS OF THE TERRITORIAL APPROACH IN THE TEACHING OF GEOGRAPHY IN BASIC EDUCATION IN CENTRO DE ENSINO MÉDIO SANTA RITA DE CÁSSIA, PALMAS-TO}

\begin{abstract}
This work aims to present some reflections about the approach's profile in the geography teaching in Basic Education. The main goal is to identify how the Centro de Ensino Médio Santa Rita de Cássia, Palmas - TO is presenting the theme in question and what notion the students in the last years of Basic Education are having on the concept of territory. Afterwards, it aims to identify the main difficulties and propose suggestions. The considerations presented here are basedon bibliographical research on the theme and on a case study in school, in 2015. Concludes that the teaching needs to be revised and deepned. The territory needs to be taught at the school in a broader dimension of its meaning and social relations in which is present.
\end{abstract}

Key Words: Territory; Basic Education; Geography.

\footnotetext{
${ }^{1}$ Graduado em Geografia pela Universidade Federal do Tocantins (UFT). Mestrando do Programa de PósGraduação em Geografia (PPGG) da UFT. Email: silvaldo@mail.uft.edu.br

${ }^{2}$ Doutora em Geografia pelo Instituto de Estudos Sócio Ambientais (IESA) da Universidade Federal de Goiás (UFG). Professora Adjunta da Universidade Federal do Tocantins (UFT) no curso de Geografia e no Programa de Pós-graduação em Geografia (mestrado) campus de Porto Nacional. Email: marcileia@uft.edu.br
}

Sociedade e Território - Natal. Vol. 28, N. 1, p. 156-173. Jan./Jun. de 2016 


\section{UN ANÁLISIS DE LA ENFOQUE TERRITORIAL EN ENSEÑANZA DE GEOGRAFÍA EN EDUCACIÓN BÁSICA EN EL CENTRO DE ENSINO MÉDIO SANTA RITA DE CÁSSIA, PALMAS-TO}

\section{Resumen}

Este trabajo presenta algunas reflexiones sobre el perfil del enfoque territorial en la enseñanza de la Geografía en la Educación Básica. El objetivo principal de esta investigación es identificar cómo el Centro de Ensino Médio Santa Rita de Cássia, Palmas - TO están presentando el tema en cuestión y qué concepto los estudiantes de los grados finales de la educación básica están tomando del territorio. A partir de ahí, identificar las principales dificultades y proponer sugerencias. Las consideraciones que aquí se presentan se basan en la investigación bibliográfica sobre el tema y la realización de un estudio de caso en la escuela, en el año 2015. Concluye que dicha enseñanza de lo concepto geográfico en la educación básica debe ser revisado y mejor profundidad. El territorio debe ser enseñado en la escuela en una dimensión más amplia de su significado y las relaciones socias en la que es presente.

Palabras clave: Territorio; Educación básica; Geografía.

\section{INTRODUÇÃO}

O território é um dos conceitos geográficos, porém não exclusivo da Geografia, que pode dar suporte ao entendimento das práticas sociais, em qualquer escala geográfica. Isso é possível pelo fato da maioria das relações da sociedade estar ligada a uma questão territorial, que precisa ser entendida como ponto de partida para as possíveis intervenções nos problemas existentes.

De acordo com Cavalcanti (2011), a compreensão deste conceito e seu uso na análise da realidade pode permitir uma visão mais abrangente. Além disso, devemos considerar que são as práticas espaciais que dão origens aos diferentes territórios, a serem discutidos no Ensino de Geografia na Educação Básica.

O ensino do território, de certo modo, é complexo por exigir um nível de interpretação bastante profundo no entendimento dos conceitos e processo espaciais relacionados. Isso ocorre principalmente pelo fato do seu significado ser amplo, permeando entre diferentes perspectivas de interpretação e pela necessidade de ser analisado em conjunto com outros conceitos geográficos.

A complexidade existe até mesmo no ambiente acadêmico, na fase de formação do professor de Geografia, o qual pode enfrentar desafios ainda maiores para promover tal abordagem na Educação Básica. Com isso, há necessidade de entender como ocorre a 
compreensão do território, pelos educandos, pois, é um conceito fundamental para o entendimento e significância no Ensino de Geografia.

Considerando tal situação, o principal objetivo da pesquisa foi identificar como a escola em questão está apresentando o tema em questão e qual noção os alunos das séries finais do Ensino Básico estão tendo de território. A partir daí, identificar as principais dificuldades existentes na abordagem do território no Ensino de geografia, e, consequentemente, propor sugestões para as práticas dos professores desta Ciência.

Para a realização do trabalho usou-se pesquisas bibliográficas sobre o tema abordado para o entendimento mais amplo das questões tratadas. Além disso, foi realizada também, uma pesquisa de campo, pois, "esta modalidade fundamenta-se no contato direto com os sujeitos da pesquisa e mesmo com o contexto no qual estão inseridos” (BISPO, 2012, p.76). A pesquisa foi desenvolvida no Centro de Ensino Médio Santa Rita de Cássia, em Palmas-TO, onde foram realizadas aplicações de questionários a todos os professores de Geografia e a 70 alunos, distribuídos ente 14 turmas regulares do ensino médio e na modalidade de estudo de caso, a qual é mais adequada para o perfil dos objetivos a serem alcançados, principalmente pelo "fato de que o estudo de caso focaliza uma situação, um fenômeno particular, o que o faz um tipo de estudo adequado para investigar problemas práticos” (DEUS, 2010, p.05).

Após uma primeira análise das respostas dos alunos, considerando pequenas diferenças das representações entre as diferentes séries, foi conveniente optar pela tabulação dos dados de forma conjunta. Com isso, foi feita a análise de todos os questionários, agrupando as respostas conforme as aproximações entre elas. Em seguida, foram calculados os percentuais de cada conjunto de idéias em relação ao total de questionários aplicados na escola. As respostas de cada docente foram analisadas individualmente e, posteriormente, correlacionadas para a interpretação das idéias de território dominantes nas praticas de ensino, na escola onde foi realizado o estudo de caso.

O estudo foi realizado Centro de Ensino Médio Santa Rita de Cássia, em Palmas-TO, considerando que nela estudam educandos de diferentes bairros do entorno. Isto possibilita uma noção mais ampla sobre o tema em estudo, pois:

[...] uma escola, como caso, deve ser estudada como um sistema delimitado, embora a influência de diferentes aspectos que se ligam a esse sistema, como o contexto físico, sociocultural, histórico e econômico em que está inserida a escola, as normas da Secretaria de Educação etc., não deva ser ignorada. (MAZZOTTI, 2006, p. 05). 
A pesquisa de campo busca a identificação da representação de território dos alunos e professores, pois, "é uma das perspectivas de entendimento da elaboração e veiculação de conceitos e imagens da realidade" (CAVALCANTI, 2001, p.33).

Elaborou-se o artigo a partir da análise qualitativa e quantitativa dos questionários baseando nos estudos teóricos. São consideradas as reflexões produzidas nestes estudos e durante a vigência da graduação, em especial os estágios, nos quais foi possível perceber indícios de que a abordagem do conceito geográfico se dava de forma pouco satisfatória.

\section{IMPLICAÇÕES E ABORDAGEM TERRITORIAL NA EDUCAÇÃO BÁSICA}

O território é um conceito geográfico de dimensão ampla, que está presente na maioria dos estudos voltados a compreensão das relações sociais. É muito comum o uso do termo em sentidos diferenciados, conforme a abordagem em que é inserido. Desse modo, seu entendimento pode ser mais eficaz quando há o conhecimento das principais perspectivas que o define.

Território tem sido uma expressão ambígua que pode designar desde um espaço social qualquer, como predomina no nosso censo comum e entre alguns geógrafos, até um espaço marcado e definido por determinadas espécies de animais, seu espaço de sobrevivência, como é definido pela etologia (HAESBAERT, 1997, p. 33).

Esta série de sentidos impregnados na definição de território acaba causando confusão no seu entendimento, se levar em consideração todos os detalhes que os diferentes autores atribuem nas diferenciações de suas abordagens. É impossível discutir este conceito sem tomar uma posição mais ou menos definida sobre seu significado e, ao mesmo tempo, sem desconsiderar a sua amplitude no campo das Ciências Sociais, como é o caso da Geografia.

Diante desta questão, uma alternativa importante é considerar as três vertentes que Haesbaert (1997) define como básicas, diante das abordagens conceituais de território: a "jurídico-política, marjoritária," em que o território é visto com uma perspectiva de dominação e poder, sobretudo por parte do Estado; a "cultural (ista)", na qual o sentido simbólico e o subjetivo domina; a "econômica", que é ligada ás relações capital-trabalho, abrangendo a dimensão conflituosa das classes sócias.

Estas diferentes abordagens não são, necessariamente, isoladas entre si. Pode haver inter-relação entre todas ao mesmo tempo, conforme a dimensão do processo analisado. Neste 
sentido não é uma boa opção optar, exclusivamente, por alguma delas, mas sim compreender a essência do todas, pois, em nenhum conceito de território a separação entre elas é nítida.

\begin{abstract}
O território significa articulações sociais, conflitos, cooperações, concorrências e coesões; é produto de tramas que envolvem as construções (formas espaciais), as instituições, redes multiescalares, as relações sociais e a natureza exterior ao homem; é objetivo material e subjetivo-imaterial ao mesmo tempo ( SAQUET, 2009, p. 88).
\end{abstract}

Este autor, por exemplo, defende a vertente econômica, mas, mantendo relação com as demais. Do mesmo modo, Haesbaert (1997) desenvolve uma abordagem cultural de forma aberta, afirmando que o território envolve simultaneamente uma dimensão simbólica, cultural, concreta e política. Santos (1977) adota um conceito de território, como sendo "território usado", partindo da idéia de fragmentação, uso e controle do espaço. Rafestin (1993) citado por Flavio (2011), desenvolve uma abordagem "jurídico-política", com forte ligação às relações de poder, entretanto, mantém também ligação com as outras vertentes, sobretudo com a "econômica e social".

Partindo desta imbricação entre as diferentes abordagens, convém desenvolver uma compreensão sobre a dimensão territorial mais presente no contexto dos educandos. "A construção dos conceitos ocorre pela prática diária, pela observação, pela experiência, pelo fazer" (CALLAI, 2003, p. 103). Desse modo, a abordagem territorial no ensino básico, pode ter um bom aproveitamento partindo do estudo das relações estabelecidas no lugar do aluno.

"Na Geografia Humanística, lugar é o espaço que se torna familiar ao indivíduo, é o espaço do vivido, do experienciado" (CAVALCANTI, 2001, p.89). Neste contexto, a discussão dos processos sociais ligados a esta categoria de análise requer a noção de identidade, memória, e patrimônio, que são conceitos relacionados às questões territoriais presentes no cotidiano dos educandos.

Isto pode permitir a fundamental compreensão da territorialidade, que "significa as relações sociais simétricas ou dessimétricas que produzem historicamente cada território" (SAQUET, 2009, p. 79). Sem entendê-la é mais complexo identificar a importância do território nas relações sociais das quais faz parte. Isto pode diminuir a importância do estudo do território na Educação Básica. 
Os jovens escolares, em sua experiência no lugar, participam das práticas espaciais formadoras de territórios, que tem sua lógica na multiterritorialidade e nas múltiplas escalas, eles próprios são sujeitos formadores de múltiplos territórios. Portanto, a compreensão desse conceito vinculado às relações de poder, à estratégia de um grupo social que se materializa num lugar, em contextos históricos e geográficos determinados, na produção de identidades e de lugares, no controle do espaço, os ajuda a compreenderem melhor suas próprias práticas espaciais. (CAVALCANTI, 2011, p. 07).

Partindo desta premissa é possível considerar a compreensão do conceito de território, pelos educandos, como um requisito básico para Ensino de Geografia. O não domínio do conceito de território pelos educandos pode dificultar a eficácia desta ciência, quanto à contribuição na formação social. Por outro lado, o domínio básico dos seus conceitos possibilita o entendimento das práticas sociais estabelecidas no espaço geográfico.

De acordo com Sousa (2012) a abordagem conceitual no Ensino de Geografia tem sido mal explorada, e, às vezes, negligenciada, causando perda de sentido e simplificação dos conteúdos trabalhados em sala aula. Isto acaba distanciando a relação da disciplina com a realidade do aluno, sendo que ela pode, conforme a abordagem dos seus conceitos, fomentar o olhar do educando sobre as relações sociais, desde a escala local à global.

Todas as experiências cotidianas dos alunos estão ligadas a determinadas questões territoriais que sendo entendidas torna mais fácil a compreensão das forças que fomentam as relações sociais presentes. Neste sentido, ignorar a importância da compreensão de território, pode ser um grande prejuízo no desenvolvimento do sujeito social.

\footnotetext{
Compreendendo seu lugar e os territórios formados em suas proximidades, como uma espacialidade, o aluno terá uma convicção de que aprender elementos do espaço é importante para compreender o mundo, na medida em que ele é uma dimensão constitutiva da realidade, e estará, com isso, mais motivado para estabelecer com os conteúdos apresentados uma relação de cognição, colocando-se como sujeito de conhecimento (CAVALCANTI, 2011, p. 10).
}

Desse modo podemos entender que o contexto do aluno é de extrema importância nos estudos sobre território. Entretanto, isso não exclui a importância das abordagens dos processos externos ao cotidiano, pois o conhecimento deve ser produzido de forma ampla. Isto exige a consideração das diferentes escalas e da relação entre elas, bem como, a mudança da forma de abordagens em certas situações. Os alunos do meio urbano, por exemplo, precisam entender o seu contexto e também a realidade do espaço no campo. 
O surgimento de novas formas de gestão, novos seguimentos profissionais, novos trabalhadores e a desterritorialização de milhares de famílias do campo não pode ser tratado como algo corriqueiro, pois esses elementos possibilitaram novos conteúdos à mobilidade do capital, com implicações profundas nas relações capital-trabalho, que precisam ser investigados à luz das mudanças nas relações sociais de produção, mas, fundamentalmente com prioridade nas novas formas de trabalho e seus desdobramentos para as ações políticas dos trabalhadores (MENDONÇA, 2004, p. 103)

Neste sentido, pode ser uma boa alternativa recorrer aos estudos da abordagem "poltica e social", de território, a qual pode contribuir no entendimento das contradições sociais desta dimensão. Os conflitos agrários envolvendo trabalhadores rurais e comunidades indígenas, por exemplo, não tem seus motivos entendidos por parte da população leiga. Razão pela qual, presenciamos facilmente críticas da própria classe trabalhadora desfavoráveis aos movimentos sociais do campo.

O aluno, um sujeito social, independentemente de onde resida, precisa saber as razões dos conflitos territoriais presentes no campo, pois este reflete em muitos problemas existentes meio urbano. É importante que os alunos possam sair da Educação Básica entendendo, por exemplo, que os posseiros que hoje são criticados é uma

[...] parcela dos camponeses sem terra, que vêm historicamente lutando numa ponta contra a expropriação que os gera e, na outra, contra os jagunços, "gendarmes de plantão" dos latifundiários especuladores e grileiros (OLIVEIRA, 2001 p. 190).

O entendimento destes aspectos, pelos sujeitos sociais, pode ajudá-los adotar posturas favoráveis ao desenvolvimento de opiniões mais flexíveis sobre conflitos territoriais, presentes nas diversas classes da sociedade. Isto faz parte da contribuição que a geografia pode ter na formação social dos alunos.

Diante desta importância que o território assume nas práticas sociais é pertinente haver preocupação quanto à sua abordagem no ensino básico, pois, mesmo com a complexidade da sua definição, sua compreensão é fundamental para o entendimento de diversos conteúdos geográficos. As dificuldades abrangem diversos fatores relacionados aos discentes e docentes, que precisam ser melhor entendidos na busca de alternativas para uma abordagem satisfatória do referido conceito geográfico.

Neste contexto, o estudo de caso realizado nesta pesquisa traz contribuição para um melhor entendimento sobre a forma como é trabalhada a definição de território e os processos relacionados na Educação Básica. Os resultados da pesquisa apontam os principais problemas 
enfrentados pelos docentes e as confusões no entendimento dos alunos da escola campo, trazendo direcionamentos para a busca de melhoria no processo de aprendizagem referente aos conteúdos territoriais.

\section{ABORDAGEM TERRITORIAL: REPRESENTAÇÕES DE ALUNOS E PROFESSORES}

A pesquisa foi realizada no Centro de Ensino Médio Santa Rita de Cássia, localizado na região Sul de Palmas, na Rua Minas Gerais, APE-SE , 01, no Bairro Aureny I. Palmas, a capital do Estado do Tocantins, esta localizada à margem direita do Rio Tocantins, ficando $805 \mathrm{~km}$ de Brasília, a capital federal, conta com aproximadamente 265 mil habitantes, conforme estimativa do IBGE (2010) para 2014.

O bairro Aureny I é um dos diversos bairros localizados fora do plano diretor inicial de Palmas, resultante do crescimento acelerado e desordenado da cidade. Conta com uma população bastante heterogênea, com grandes diferenças de classes sociais.

A instituição onde o estudo de caso foi realizado trata-se de uma escola pública estadual que atendia no período da pesquisa, 2153 alunos sendo 1905 de turmas regulares do ensino médio e 248 de turmas da EJA. A instituição atende alunos de outros bairros também, sobretudo, daqueles que estão ao seu entorno, nos quais residem a maior parte dos alunos e professores que participaram da pesquisa.Quanto ao quadro de professores de geografia, a escola conta com uma boa equipe. Todos possuem formação na área de atuação, sendo a maioria pós-graduados na área da Educação. Além disso, todos têm experiência significativa na atuação docente, variando de 18 a 28 anos de carreira no ensino básico.

\section{Representações de território dos alunos e dos professores}

Para identificar a representação de território dos alunos, sobre sua definição do conceito, foram feitas as seguintes perguntas: 1. O que você entende sobre território? 2. Quais os territórios que fazem parte de sua vida? 3. Palmas é um território? Por quê? 4. Seus professores de geografia trabalham o tema território em sala de aula? 5. Como os professores de Geografia ensinam sobre território em sala de aula?

A definição de território predominante, identificada na primeira questão, é de que seja uma área pertencente a alguém. Conforme as respostas o entendimento do termo está muito 
ligado a noção de poder e limite, sendo apontadas como território área ocupada, área de abrangência, de pertencimento e etc. Mesmo assim, as idéias de território dos alunos foram bastante diversificadas, apresentando basicamente três noções distintas.

A primeira, estabelecida por $42 \%$ dos alunos entrevistados, foi a noção de poder sobre área delimitada, aproximando da perspectiva “jurídico-política, marjoritária”, com respostas como:"Território pode ser onde você mora ou frequenta, seu país, cidade ou estado","Território é uma área grande de terra que pertence a algum governo", "Território é uma área dominada por alguém".

A segunda noção, apresentada por 30\%dos alunos, tende a definir o território apenas com uma área de terra, ou terreno, sem relação demonstrar as relações de poder. As respostas foram: "É uma porção de terra, pode ser grande como o território brasileiro ou pequeno", “Território pra mim é um lugar, uma área que é dividida e marcada com quilometragem”,

"Território é um espaço ou terreno onde se faz casas e etc.".

Outra noção, demonstrada por $28 \%$ dos alunos, foi a de pertencimento e afetividade, aproximando um pouco da perspectiva "culturalista", de território, mas mantendo uma certa ligação com a "jurídico-política, majoritária”, com respostas do estilo: "Território é um lugar habitado por pessoas, que fazem dele seu lar e constrói suas casas e famílias", "Território é o lugar onde eu, você ou várias pessoas podem habitar”, “(...) onde vivo, a terra na qual eu vivo, onde é habitada por algum ser,".

Já as vertentes econômica e social de território, que muito contribui para o entendimento dos conflitos sociais, não aparecem nas noções de território dos alunos. E isso é preocupante, pois, muitas práticas cotidianas deles ou de seus familiares possivelmente permeiam nas relações existentes entre o capital e o trabalho.

Esta diferenciação de noções deixa claro que não é uma boa alternativa focar no ensino do conceito apenas sobre uma perspectiva, mas sim, fomentar o entendimento dos alunos sobre os processos sociais que o envolve. Um caminho que pode permitir o uso do território pelo sujeito social, na interpretação de diferentes situações práticas vivenciadas no cotidiano.

Nas respostas da segunda questão os alunos apontaram quais os territórios que fazem parte de sua vida. Citaram diversos exemplos distribuídos em duas perspectivas que foram identificadas. A primeira apresentada por $60 \%$ dos alunos tem maior aproximação da realidade local: "O lugar onde eu moro, porque é onde eu me habito”, “(...) cidade onde eu 
moro e de onde eu nasci", "O território que mais faz parte da minha vida é a Igreja e a convivência com meus familiares".

A outra perspectiva, apresentada por $30 \%$ dos alunos, abrange um contexto amplo. As respostas saem da escala local passando para a estadual e nacional”,“(...) território brasileiro, pois é o que eu vivo", "O Tocantins, Goiás, com quase toda a região do Cerrado", "Os territórios que fazem parte da minha vida é nacional Brasil, regional Palmas, e da região norte".

É possível perceber que quando o território é tratado no nível da vivência e experiências, os alunos tendem a retomar à noção de identidade com o lugar e de afetividade, o que distanciam um pouco da idéia de poder político, e aproximam da dimensão simbólica, tendo como referência a família, a comunidade e a ligação com o local onde estabelece suas relações sociais.Um total de $10 \%$ dos alunos não responderam a questão de numero dois.

Enquanto isso, na questão em que os alunos tinham que responder se Palmas era um território, a terceira questão, 93\% responderam que sim, justificando com base nas diferentes noções: "Porque território é o espaço ou um lugar onde sua extensão é limitada", “(...) faz parte de um estado que faz parte de um país que também faz parte de um continente"."Palmas é um território porque é uma terra onde pessoas moram, em um lugar que tem um governo","Porque Palmas é uma área dividida e também marcado seu território", "Porque é o lugar onde eu moro","Porque em Palmas há um grupo de pessoas que habitam esse local","Porque ela é delimitada. (...) em posse de um líder que é o prefeito".

Dentre os alunos que responderam os questionários apenas um educando $(1,3 \%)$ afirmou que palmas não é um território, por ser uma área pequena. Os demais $(5,7 \%)$ não responderam a questão.

No que refere à abordagem do território no ensino de Geografia, a maioria dos alunos $(90 \%)$ afirmou que os professores trabalham o tema em sala de aula. Os demais (10\%) não responderam.

Com relação à ultima questão, 28,5\% dos alunos apontaram as metodologias e recursos usados pelos professores no ensino do conceito geográfico: "Com apresentação de slides sobre algum continente, com explicações e trabalhos","Mostrando em mapas explicam sobre o conteúdo dialogando com os alunos, passando atividades, fazendo dinâmicas", "Com aulas dinâmicas e ilustradas". 
Entretanto, uma parcela maior $(61,5 \%)$ mencionou a forma como os professores abordam o tema: "Pelo que ainda lembro estudávamos sobre mapas e guerras territoriais, conflitos entre países pela posse de algum território", "Eles nos ajudam a entender o que seja. E nos explica como é e como funciona o território onde moramos", "Na verdade Geografia sempre vai falar sobre problemas relacionados ao território. Então os professores acabam sempre por explicar a respeito de território", "Eles ensinam explicando o que é suas características e etc.","Eles ensinam sobre conflitos constantes que países do mundo têm entrando em guerra. E falam sobre fronteiras de estados".

Conforme a representação dos alunos pode-se, perceber inúmeras implicações no ensino de território e muitas confusões quanto ao entendimento do conceito, mesmo se tratando de turmas do ensino médio. Entretanto, para melhor compreensão destes aspectos é preciso considerar as representações dos docentes de Geografia da escola campo. Uma analise que permitirá a comparação entre as ideias dos principais sujeitos envolvidos, diretamente, no processo de ensino.

Para a identificação das idéias de território predominante entre os professores e do perfil da abordagem do conceito na escola campo, foram feitas diversas perguntas, tais como: 1. Como você define território? 2. Em sua opinião, qual a importância da noção do conceito território no Ensino de Geografia, na Educação Básica? 3. Quais as principais dificuldades em trabalhar este conceito no ensino básico? 4. Como você trabalha o conceito de território em suas aulas? 5. Que sugestão você daria para melhorar a abordagem territorial no Ensino de Geografia, na Educação Básica?

Os professores que participaram da pesquisa são identificados pelas letras A, B, C, D e E. Isto permitiu a análise individual e coletiva das idéias que eles apresentaram sobre a abordagem territorial na educação básica. Através das respostas dos professores, correlacionadas às representações dos alunos, foi possível entender a forma como o território é tratado na escola campo. Isso possibilitou uma noção ampla sobre diversas implicações da abordagem territorial na Educação Básica, sobretudo, das práticas docentes e do entendimento dos alunos.

As definições de território, referente à primeira questão, apresentadas pelos professores de Geografia da escola foram bastante diversificadas, entretanto, apresentam entre si uma proximidade no conteúdo. Todos definiram o território baseando-se na noção de poder sobre área delimitada, aproximando mais da perspectiva “jurídico-política, majoritária". 
O professor A afirma que "no conceito tradicional é área, e o espaço onde um estado está instalado e onde ele exerce a sua soberania (Conceito de Território para a Geografia)"No entendimento da professora B território é "uma parte da Terra que pode ser dividida em continentes, países, estados, cidades. Cada parte é importante e necessita da outra para crescer como nação, economicamente e em vários aspectos geográficos".

Para a professora $\mathrm{C}$ "território não se restringe somente às fronteiras entre países, regiões, estados e municípios". A professora D define com "espaço delimitado sob o domínio de alguém ou de um grupo, de acordo com um conjunto de regras estabelecidas". A professora E afirma que é "uma área delimitada de onde pode representar um país, uma região, um continente, ou seja, um poção do espaço".

Embora todos os professores tenham demonstrado considerar o território como um conceito de extrema importância, somente as professoras C, D e E responderam qual a importância da noção do conceito território no Ensino de Geografia na Educação Básica, afirmando que ele é trabalhado com ênfase.

A professora $\mathrm{C}$ afirma que "justamente com a definição de espaço geográfico, paisagem, lugar e região já está inserido o conceito território. Quando falamos de Região Norte, automaticamente falamos do território onde se estabelece esta região e o mesmo acontece quando falamos de fronteiras". Para a professora D "nós somos os construtores do espaço geográfico, que abrange o espaço físico e as relações sociais existentes”.Já a professora E responde que o conceito é enfatizado, "porque território corresponde ao espaço geográfico socializado".

Os demais afirmaram que não há abordagem específica sobre o território. Segundo eles o conceito é trabalhado dentro das discussões em que ele se insere. O professor A considera que o território não é trabalhado especificamente, mas sim "abordado conforme surge a necessidade. Em nenhum momento é abordado com ênfase de importância destacada". No mesmo sentido, a professora B considera que o não é abordado "em tópicos distintos, mas sim no geral".

Com base nestas respostas pode-se afirmar que o conceito território não é muito focado na escola em que se realizou a pesquisa. De certo modo, isso dificulta o entendimento da sua definição pelos educandos. Entretanto, não impede a compreensão das questões territoriais, já que elas são vistas na abordagem de outros conteúdos. "O conceito deve ser 
visto como instrumento de análise, funcionando como ferramenta de compreensão para uma dada conjuntura" (SOUSA 2012, p. 14).

Neste sentido, os professores afirmaram que os alunos conseguem entender o significado de território abordado na escola e em suas aulas. Apenas a professora E afirmou que, às vezes, ocorre confusão entre território e outros conceitos da Geografia, como é possível entender nas respostas dadas.

Na opinião do professor A os alunos teriam dificuldades em "definir sua compreensão de território, apesar de empiricamente saber o seu significado. Isto porque nossos alunos encontram muitas dificuldades em escrever seu conhecimento sobre a maioria dos temas".A professora B afirma o que os alunos entendem o significado do conceito geográfico justificando que "em cada etapa do ensino e na abordagem de território se faz um levantamento de cada superfície da Terra, abrangendo desde áreas maiores até áreas menores sendo conhecidas por todos".

A professora $\mathrm{C}$ considera que os alunos entendem o conceito, justificando: "porque quando falo em Tocantins, eles já tem o entendimento que falo de um território delimitado por fronteiras que pertencem ao Estado do Tocantins. A professora D diz que os discentes compreendem "através das aulas práticas, estudos da formação territorial, divisão regional, urbanização, por exemplo, quando peço para eles ir a campo e coletar dados, seja estatístico, seja imagens ou depoimentos, sistematizá-los e tirar conclusões, percebendo que faz parte desse contexto". Já a professora E considera que "nem sempre, pois, às vezes é difícil distinguir o conceito de território, espaço e lugar".

Com relação à terceira indagação, as professoras D, C e E apontaram como principais dificuldades, a confusão que acontece no entendimento do significado de território e a inserção do tema no cotidiano dos alunos. Segundo elas, há dificuldades também em razão da grande abrangência do conceito. O professor A e professora $\mathrm{D}$ afirmaram não ter complexidade, pelo tema se tratar de um conceito presente direto ou indiretamente nos conteúdos de Geografia.

Quanto às suas praticas pedagógicas, tratadas na quarta questão, os docentes afirmaram trabalhar o conceito de território através de diversas metodologias quando estão trabalhando conteúdos em que cabe a discussão. As divisões político-administrativas foram bastante focadas como conteúdos relacionados aos territórios, o que revela a importância da 
fronteira como limite, jurídico-política, e das relações de poder na abordagem territorial dos professores.

O professor A disse que trabalha o território em sala "naturalmente, dentro do contexto do assunto trabalhado, não dando ao mesmo destaque espacial”. Para a professora B “de acordo com cada tema a ser abordado, há variação de território, sendo definida a área ou local com a nomenclatura de variação: continente, país, estados”. A professora afirmou o seguinte: "Trabalho quando estudamos regiões, estados, municípios, países, continentes, biomas e outros. Nos apoiamos em conceitos, mapas e data-show para delimitarmos com mais clareza os espaços. Não fica de fora pesquisas científicas e aulas a campo quando possível”.

No mesmo sentido, a professora D afirma que trabalha o conceito com os alunos "através de aulas práticas onde eles coletam informações, sistematizam e apresentam através de vídeos, documentários, seminários ou exposições”. A professora E disse que trabalha "através de explicações e exemplos, como por exemplo: território brasileiro; dentro do território brasileiro, território do narcotráfico, dentre outros".

A última questão pedia que os professores dessem sugestão para a abordagem territorial na Educação Básica. Foram dados diversos apontamentos, tanto no que tange ao uso de recursos metodológicos quanto no que se refere ao tratamento dos conteúdos que evolvem a discussão territorial.

O professor A sugeriu que, "o conceito de território é algo que deve ser inserido nos educandos de forma natural, demonstrando que ele pode ser contextualizado em diferentes situações". Para a professora C é preciso "aprofundar mais as pesquisas e estudos, acompanhando de aulas mais práticas, com uso de recursos audiovisuais".

No entendimento da professora $\mathrm{D}$, o território deve ser trabalhado esclarecendo que as “transformações sociais e espaciais ocorrem em algum lugar e que este é constituído pelo ser humano de acordo com as técnicas e tecnologias de seu tempo e que essas transformações se refletem nas paisagens e nos comportamentos sociais no meio ambiente”. Já a professora E entende que é preciso "usar uma linguagem acessível ao nível dos alunos, ou seja, adaptar os conceitos dos livros a uma linguagem que os mesmos possam compreender".

Com base nas respostas dadas pelos professores, foi possível notar que os professores consideram uma boa alternativa trabalhar o conceito de território juntamente com a discussão sobre as transformações espaciais, abrangendo os mais diversos conteúdos e mantendo a 
aproximação da realidade do aluno. Além disso, chamam atenção para o uso de metodologias adequadas, que possam facilitar o envolvimento dos educandos na discussão.

\section{CONSIDERAÇÕES FINAIS}

Após a análise dos resultados da pesquisa foram possíveis várias considerações a respeito da abordagem territorial no Ensino de Geografia. Dentre elas, merecem destaque as referentes às representações de território dos alunos e dos professores da escola campo, pois são reflexos da forma como a conceito geográfico vem sendo tratado no Ensino Básico.

As definições de território identificadas durante a pesquisa nos levam a entender que este conceito é explorado limitadamente, pois, no geral, apenas a perspectiva "jurídicopolítica, marjoritária" é enfatizada, tanto no entendimento dos professores como dos alunos. As abordagens "culturalista" aparece levemente e a "econômica" e "social" é basicamente desconsiderada.

Ao confrontarmos as representações de território dos alunos com as representações de seus professores, vemos que elas são bastante semelhantes, o que significa que a compreensão do conceito acontece da forma como tal conhecimento é abordado na sala de aula. Isto significa que há necessidade da abordagem territorial no ensino básico transcender as noções de limite, poder, e pertencimento. É preciso ser inserido em todas as questões sociais trabalhadas em sala de aula, podendo ampliar o entendimento dos alunos sobre as relações que vivenciam no cotidiano, pois, a "abordagem do lugar contempla alguns aspectos da prática espacial que contribui, de modo articulado, com a construção do conceito de território" (CAVALCANTI 2011, p. 6).

A perspectiva "culturalista", pouco presenciada na pesquisa, pode permitir uma aproximação maior do aluno de suas práticas cotidiana. Quando os alunos apontaram os territórios que fazem parte de suas vidas, a maioria $(60 \%)$ deles retomaram à questão do pertencimento e afetividade, saindo um pouco da noção de poder para uma vinculação com identidade e o lugar. Esta questão permite entender que há uma diferença de representações entre a dimensão conceitual e a processual do território, pois, quando se trata de exemplos mais práticos há maiores expressões de aspectos das territorialidades dos alunos.

Quanto à forma de trabalhar o território em sala de aula, as versões dos alunos e professores da escola coincidiram. Seus depoimentos deixaram claro que não há muita ênfase na abordagem do tema. Normalmente, o conceito é discutido ao longo de outros conteúdos. 
Entretanto, isso não é muito preocupante, pois, de fato não é possível focar muito em cada conceito ou categoria da geografia na educação básica. A questão a se pensar é o fato da discussão pouco aproximar do cotidiano dos alunos, devido estar inserida em assuntos amplos, conforme demonstrado nos resultados da pesquisa.

O fato da perspectiva de território "jurídico política marjoritária”, dominante na educação básica, ser mais enfatizada nos livros didáticos, parece incentivar os professores a distanciarem da escala local. O conceito é trabalhado dando maior atenção aos conflitos existentes entres os países e estados, considerando a fronteira jurídico-política como base de limites. Neste contexto, é notável a necessidade de considerar também, outros tipos de territórios no ensino básico, para possibilitar uma abordagem imbricada nas diferentes perspectivas do conceito e nas praticas sociais dos educandos.

Neste sentido, uma boa sugestão seria uma interpretação mais abrangente do território, transcendendo a idéia de vínculo direto com o solo. Assim, seria possível inserir na discussão as diversas territorialidades encontradas no meio urbano, como "os territórios em constantes movimentos" (VALVERDE, 2004, p. 125). Território da prostituição, do narcotráfico, dos moradores de rua, da criminalidade, da sociedade civil são exemplos citados pelo mesmo autor.

Conforme os resultados da pesquisa, a perspectiva "econômica" e social de território precisa ser mais explorada, pois, a maioria das questões sociais é estudada através desta vertente, em conjunto com as demais aqui abordadas. Como foi explicado no inicio, elas são inter-relacionadas, portanto, nenhuma pode ser ignorada no processo de ensino ou em outras produções de conhecimento.

Explorar melhor a abordagem territorial na Educação Básica seria, em síntese, tratá-la como eixo de interpretação de grande parte das relações contraditórias da sociedade. Neste sentido, vale lembrar das sugestões de alguns professores, os quais indicaram como alternativa, trabalhar o conceito nos momentos necessários. Isto requer do docente um conhecimento amplo do significado de território em Geografia, para que possa identificar sua essência nas questões sociais.

É importante ressaltar as sugestões metodológicas dos professores da escola campo em relação à abordagem territorial, pois, a experiência docente não deve ser desconsiderada na busca de melhorias no processo de ensino. De acordo com eles, o tema deve ser trabalhado 
fazendo uso de uma série de recursos e procedimentos, a fim de despertar o interesse dos alunos, sobretudo pelo fato de ser um conteúdo complexo.

A realização de trabalho de campo, a discussão do conceito em sala, uso de recurso audiovisuais, realização de entrevistas, pesquisas bibliográficas, trabalhos em grupos e apresentação de seminários foram as principais sugestões e que também podemos concordar. São basicamente as mesmas metodologias para trabalhar outros conceitos geográficos. $\mathrm{O}$ principal cuidado está no tratamento do conceito durante as aulas e a sua articulação com os outros conteúdos e com o contexto dos educandos.

Pode-se entender, com base nos estudos realizados, que a abordagem territorial na Educação Básica precisa ocorrer de modo mais abrangente, podendo contribuir mais com a importância da Geografia para formação social e crítica dos educandos. Tal avanço não consiste em um aprofundamento demasiado na discussão conceitual, mas sim no entendimento das territorialidades presentes na própria realidade do aluno, nas diferentes escalas geográficas. Um fato que requer uso do conceito geográfico em suas diferentes dimensões mantendo ligação com os demais conceitos e categorias principais da geografia.

Portanto, é preciso um ponto de partida para um melhor ensino do território, o que pode estar na mudança do tratamento do conceito nos livros didáticos e pelos professores, no sentido de possibilitar a quebra das limitações de seus significados. Isto pode permitir a identificação da essência territorial nos mais diversos temas abordados em sala de aula, tornando o conceito importante no ensino básico o quanto é no espaço acadêmico. Uma equiparação que não se sabe até que nível é possível e desejável.

\section{REFERÊNCIAS}

BISPO, Marciléia Oliveira. Cenários, olhares, tramas e cotidiano: A Educação Ambiental à luz de distintas representações e territorialidades. Tese (doutorado) - Universidade Federal de Goiás, Programa de Pós-Graduação em Geografia, Instituto de Estudos Sócio-Ambientais IESA. 2012.

CAVALCANTI, Lana de Souza. Geografia Escola e Construção de Conhecimentos. 3.ed. Campinas, SP: Papirus, 2001.

CAVALCANTI, Lana de Souza. Ensinar geografia para a autonomia do pensamento: o desafio de superar dualismos pelo pensamento teórico crítico. Revista da ANPEGE, v. 7, n. 1, número especial, p. 193-203, out. 2011. 
CALLAI, Helena Copetti. Estudar o lugar para compreender o mundo. In:

CASTROGIOVANNI, Antonio Carlos. Ensino de Geografia: praticas e contextualizações no cotidiano. 3.ed. Porto Alegre: Mediação, 2003. p. 83 -134.

DEUS, Adélia Meireles de. Estudo de caso na pesquisa qualitativa em educação: uma metodologia. Disponível em: 〈www.ufpi.br/subsiteFiles/ppged>. Acesso em: 01 dezembro e 2010.

FLÁVIO, Luiz Carlos. Memória(s) e território: elementos para o entendimento da constituição de Francisco Beltrão-PR. Disponível em:

<http://base.repositorio.unesp.br/bitstream/handle/unesp>. Acesso em: 2011.

HAESBAERT, Rogério. Desterritorialização e identidade: a rede gaúcha no Nordeste. Niterói, RJ: Ed. UFF, 1997.

IBGE - Instituto Brasileiro de Geografia e Estatística. Censo Demográfico (2010). Disponivel: <http://www.cidades.ibge.gov.br/>. Acesso em: 2010.

MENDONÇA, Marcelo Rodrigues. A modernização da agricultura nas áreas de Cerrado em Goiás (Brasil) e os impactos sobre o trabalho. Investigaciones Geográficas, Boletin Del Instituto de Geografia. Num. 55, p. 97-121, dezembro de 2004.

MAZZOTTI, Alda Judith Alves. Usos e abusos dos estudos de caso. Disponível em: Cadernos de Pesquisa, v. 36, n. 129, p. 637-651. Acesso em: 2006.

OLIVEIRA, Ariovaldo Umbelino de. A longa marcha do campesinato brasileiro: movimentos sociais, conflitos e Reforma Agrária. Estudos Avançados 15. Disponível <em: http://www.scielo.br/pdf/ea/v15n43/v15n43a15.pdf>. Acesso em 2001.

SANTOS, Milton. Sociedade e espaço: a formação social como teoria e como método. In: Boletim Paulista de Geografia, n. 54, p. 81-100, julho/1977.

SAQUET, Marcos Aurélio. Território e Territorialidades: teorias, processos e conflitos. Ed. São Paulo: Expressão Popular, 2009.

SOUSA, Roberto Ribeiro de. O conceito território no ensino de geografia: breves notas sobre abordagens negligenciadas. Disponível em: 〈www.revistaunioeste.com.br $>$. acesso em: 22 de setembro de 2012.

VALVERDE, Rodrigo Ramos Hospodar Felipe. Transformações no conceito de território:competição e mobilidade na cidade. GEOUSP - Espaço e Tempo, São Paulo, No 15, p. 119 - 126, 2004.

Recebido em Março de 2016

Aprovado em Maio de 2016

Publicado em Junho de 2016

Sociedade e Território - Natal. Vol. 28, N. 1, p. 156-173. Jan./Jun. de 2016 